\title{
Building a constructivist social learning environment through talk in the mathematics classroom
}

\author{
Esin Acar ${ }^{1}$ \\ Ayşen Y1lmaz
}

\begin{abstract}
This study aimed to create a constructivist learning environment wherein third grade students talk to problem solve, which is different from traditional approaches to math learning. The study focused on the group talk and discussions to understand the students' actions and interactions during the process of problem solving. Fifteen students and their teacher participated in the study, which was conducted within a collaborative action study design. Different types of problems were constructed including addition, subtraction, multiplication and division. Students were divided into four groups and observed for four weeks as they solved the different types of problems through group discussion. In the study, it was observed that the students who took leadership roles in the groups during the problem solving activities lead discussions. Additionally, the study found that the students, who could not solve the problems individually, were able to contribute more to the problem solving activity in the group works.
\end{abstract}

Keywords: Talk in math learning; group discussion in math learning; constructivist learning environment; small group work; elementary math

\section{Introduction}

Creating a social learning environment in a math classroom, in which knowledge is perceived numerically and problem solving activities are going on, is not an ordinary approach to implement math curriculum. Yet, one of the primary things that elementary school children consider important is the relationships with their friends, and talk is one of the most important tools for this. A large body of literature (e.g., Bauersfeld, 1979; Brown, Collins \& Duguid, 1989; Collins, Brown, and Newman, 1989; Lave, 1988; Lave,

\footnotetext{
1 Ph.D., Adnan Menderes University, Faculty of Education, Department of Elementary Education, email; esinnacar@gmail.com

2 M.Ed., Adnan Menderes University, Faculty of Education, Department of Elementary Education email; whisperofsun@gmail.com
} 
Acar, E., Yllmaz, A. (2015). Building a constructivist social learning environment through talk in the mathematics classroom. International Journal of Human Sciences, 12(1), 991-1015. doi: 10.14687/ijhs.v12i1.3123

Smith \& Butler, 1989; Greeno, 1989, Resnick, 1989; Rogoff \& Lave, 1984; Schoenfeld, 1989a; in Schoenfeld, 1992) suggests that in addition to its cognitive aspect, mathematics learning is a naturally social and constructive activity rather than a passive one.

In this study, we aim to create a constructive classroom environment via the talk in order to see if the students' performances on problem solving can change. Our inquiry seeks to understand if the students can learn or understand clearly when they talk about a math problem with their classmates in a small group. The discussion in the small student groups treated here goes beyond expressing and sharing thoughts about the given problems and is for the purpose of problem solving. Also, the research is concerned with how the discussions allow students to apply their thoughts and knowledge to work through conceptual and operational difficulties in mathematics through the group structure. Moreover, the study analyzes the role of group talk and discussion in creating a constructivist learning environment for understanding math problems.

\section{Theoretical Background}

\section{Constructivist learning environment}

Education and business have come to recognize that learning and working collaboratively in groups or teams produce the significant learning and creativity (Johnson \& Johnson, 1990; in Nelson, 1999). If learning occurs naturally by teams of people working together to solve problems (Jonassen and Rohrer-Murphy, 1999), teachers need to create an environment that allows their students to talk, discuss, and share their knowledge and help each other when needed. Although the constructivist learning environment cares about the students' personality because it is attentive to the fact that social settings can constrain learning (McRobbie and Tobin, 1997).

From the social constructivist perspective, which emphasizes the collaboration among learners in the classroom and with practitioners in the society (Lave \& Wenger, 1991; McMahon, 1997), learning should involve some different teaching methods, such as reciprocal teaching, peer collaboration, cognitive apprenticeships, problem-based instruction, webquests, anchored instruction and other methods that involve learning with others (Shunk, 2000; cited in Kim, 2001). Solving the problems with others in student learning groups may be one of the ways to bring the social constructivist perspective to a math class. In relation to the key features of these kinds of groups, Emmer \& Gerwels (2002) emphasized the interdependence among students and the importance of group interaction which allows students to make mistakes. Becoming a group work effective requires that sharing ideas, taking risks, disagreeing with and listening to others, and generating and reconciling points of view (Blumenfeld, Marx, Soloway \& Krajcik, 1996). 
Acar, E., Yllmaz, A. (2015). Building a constructivist social learning environment through talk in the mathematics classroom. International Journal of Human Sciences, 12(1), 991-1015. doi: 10.14687/ijhs.v12i1.3123

\section{How do talk and discussion in a group affect students' academic achievement?}

There are many ways to see the positive effects of peer support for students during their classroom tasks. The small group can be one of the most suitable structures for peer support. In this kind of group, students feel more comfortable for asking questions, expressing their opinions, and taking risks because it provides opportunities for trial and error (Adams \& Hamm, 1990). The limited exchange of information and explanation provide the students in collaborative seatwork for just routine learning, but if it is purposed structured conceptual learning with group tasks and ill-structured problems more open exchange and elaborated discussion are necessary (Cohen (1994). According to Weber, Maher, Powell and Lee (2008), learning can be facilitated by group discussion having new claims about the ways and about the standards used in deciding whether an argument is acceptable.

Enhancing of students' ideas may give them some opportunities to be teachers as well as learners. In collaborative learning, the opportunity of working together is provided to students with the teacher's monitoring and helps as needed (Fisher, Frey \& Rothenberg, 2008).

\section{The Use of Talk in the math teaching (Teacher's role)}

Although the constructivist classrooms includes complex learning activities, teachers or designers of these constructivist activities help learners to perform the tasks by scaffolding, guiding the problem solving process, and building in use of cognitive tools skills, such as able to replicating, modeling or representing. All of these tools can enable the learners to see phenomena in different ways (Jonassen and Rohrer-Murphy, 1999).

In mathematical thinking, students try to translate the phenomena to symbolic representation by asking some questions such as, "what, what if or how". While solving just the computational problems, students reason and infer from the data, actual life problems, occurring outside of school, may require experience. Providing a real life or realistic problem situation would be a means for inquiry by students in a group form. İdentification of the problem leads the students to work as a scientific team to find the solution (Adams and Ham with the collaboration of Drobnak and Lazar, 1996). Teachers can do this by means of cooperative tasks, which allow students to interact and improve their communicative skills (Rogoff, 1998; Rubin, Bukowski and Parker, 1998). Because during the cooperative interactions, children guide, assist and teach to their friends for problem solving and completing the assigned classroom tasks. Also, these interactions promote their learning and cognitive development (Slavin, 1987a). During the students' 

classroom. International Journal of Human Sciences, 12(1), 991-1015. doi: 10.14687/ijhs.v12i1.3123

cooperative interactions and learning in a math class, teachers monitor the learning groups and intervene to improve mathematical abilities of students.

In discussion or talk groups, students think and reflect their thoughts by using their words. So, they learn how to use language for expressing their thoughts in time. While students may pace themselves while they are working individually- they act of thought analysis, synthesis and judgment for pacing- they would have responsibility of suiting their pace in reflection to the pace of their peers (Wagner and Arnold, 1965). Therefore, the teachers should encourage the students to talk and interact, not to just for show their knowledge (Bligh, 1986). Moreover, Piggott (1997) asserts that teachers would use small groups and share mathematical journeys by encouraging collaboration in order to improve learners' team-working skills. Using other people's experiences and building on practices in different situations also make contribution to group talk and discussion.

\section{Method}

\section{Design of the study}

The study began by inquiring if group talk could be used in elementary math teaching as supportive of the constructivist learning environment. Additionally, ideas for the research came from the classroom teacher's observations of her students. Design of the study can be defined as collaborative action research because it aims to support teacher development also as well as students' development. In collaborative inquiry, the focus is on establishing a purpose, generating questions, taking action, collecting and analyzing data, reflecting, adjusting course and many times new questions to pursue (Cunningham, 2011).

This research aimed to make some improvements on problem solving activity in small groups by talking; to improve the teacher's understanding of the influence of group talk on creating a constructivist learning environment and to improve the students' problem solving processes and sociability in their math class. As Zeichner and Noffke (2001) put it, the purpose of action research is improving student learning by introducing more effective teaching strategies. And student achievement, providing opportunities for professional development and helping teachers make their practice more explicit are some expectations in this kind of research design (cited in Henning, Stone \& Kelly, 2009). 
Acar, E., Yllmaz, A. (2015). Building a constructivist social learning environment through talk in the mathematics classroom. International Journal of Human Sciences, 12(1), 991-1015. doi: 10.14687/ijhs.v12i1.3123

\section{Study Group}

In the study, fifteen third grade students and their teachers took part in the study and played an active role. The classroom teacher and the students, except one, are volunteered for the study. The teacher's willingness, who is a master student on the elementary education department, and the classroom's availability for the study directed us to this study group. The activities of students in the classroom, which took place in a little village school, were divided into four homogenous groups and asked to solve the problems in their groups by talking and discussing to each other. The homogeneity of the groups was arranged according to student success, but each group organized heterogeneously including at least one successful student having leadership capacity. While there were five students in the first group, there were four students in the second one and three students in both third and fourth groups.

\section{Data collection}

In the study, four different types of problems were prepared before the study to be assigned to the four groups. These problems are structured as addition, multiplication, subtraction and division problems. During the preparation of problems, the educational attainments were targeted to the third grade math curriculum and compatibility with students' learning levels were taken into account. The process of data collection lasted four weeks including the problem solving activities taking part each day of the week.

Before the students started to solve the problems, the task letters were distributed to the students, which intended to encourage the students to engage with the problems and become interested in the questions that they would be answering. By these letters, therefore, we aimed to make the students feel that they would play a very important role on solving a big life problem. Four different occupations were selected before creating different task letters prepared for four different groups. The common interests of students in groups were taken into consideration for choosing the professions on the task letters (See figure 1).

While the first questions of problems taking part on the activity papers handed out to the groups have just numbers without any words, second questions included both verbal expressions and numbers. Though only the verbal expressions are used in third questions, in the fourth questions it was asked that the students to create problems using the pictures on their activity papers and to solve them. The problems requiring addition, multiplication, subtraction and division in the activity papers are prepared both in the level of same 
Acar, E., Yllmaz, A. (2015). Building a constructivist social learning environment through talk in the mathematics classroom. International Journal of Human Sciences, 12(1), 991-1015. doi: 10.14687/ijhs.v12i1.3123

difficulty with different numbers for each group member and with the aim of solving them with a group together.

As well as the individual activity papers, some blank paper was handed out to the students so that they could write down their ideas about the problems. After students shared their ideas about the problems on the blank pages, more activity papers with openended questions were handed out to get students' further ideas and opinions about the activity was already assigned and students had already written down initial thoughts about on the blank pages.

You are all significant mathematicians working in space station. You were given a very important and secret mission. Your mission is to solve the math problem properly, which was given you, by talking to the other mathematicians. If you solve the problem properly, you will save our world by splitting the meteor which is approaching to our planet swiftly.

Let's save our world):

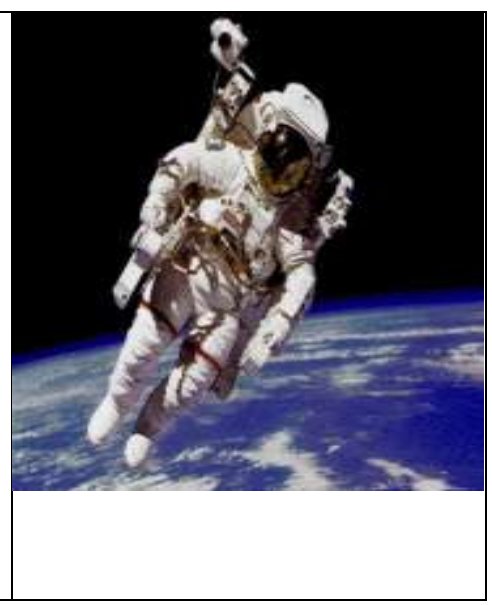

Figure1. An example letter

\section{Data analysis}

In the study, two kinds of data were acquired: the solutions written on the individual activity papers and video recording of problem solving process in groups. In parallel with the transcription of data the students' individual problem solutions were examined in order to analyze the video recorded data. Within the scope of content analysis, the coding process included the coding words for identifying themes and some new codes are reproduced that parallel the findings during the data analysis. The coding was done by two researchers separately and then they discussed the coded themes, words and situations. Although the compatibility and consistency among the codes of two researchers was high around (90\%), a math teacher working in a different elementary school also coded a part of the data. The coding of two different specialists was compared themes one-to-one. At the end of this process codes falling under the themes were tabulated for the purpose of ensuring the inter reliability. 
Acar, E., Yllmaz, A. (2015). Building a constructivist social learning environment through talk in the mathematics classroom. International Journal of Human Sciences, 12(1), 991-1015. doi: 10.14687/ijhs.v12i1.3123

\section{The analysis of the problem solving process on individual activity papers}

In the analysis of individual activity papers, which were handed out at the beginning and end of study to see if there was an alteration at the students' problem solving performances, three categories are emerged as the incomprehensible and insolvable problems, the problems, which are understandable but cannot be solved due to calculation errors and the problems solved correctly. This suggests that these categories grew out of the data more clearly.

\section{The Study}

The study consists of two practices: individual and group work. In the study, lasting a total of 4 weeks, individual activity papers were distributed on the first day of the week and students worked individually, for the rest of the week students solved the problems through group problem solving activities. The groups' works took place during the same weeks, but the activities occurred on different days for each group. Four different task letters were assigned to four different groups. Then, addition problems were assigned in the first week while multiplication, subtraction and division problems were assigned in the following weeks.

In the first step of study, the individual activity papers were handed out to the students. The students were asked to solve the problems on the papers individually and then to answer the open-ended questions on the papers distributed after the individual activity papers. Once completed, all individual activity and opinion papers were collected and evaluated.

In the second step, the group members' shared problem solving process and their discussions about the processes were video recorded in order to establish if a learning environment occurred during the problem solving discussions. However, the students' problem solving performances individually and in groups were recorded in order to see the differences between these two kinds of performances. The questions on the activity papers were differentiated. There were three kinds of problems. Illustrated problems, the problems illustrated and presented as verbally at the same time, and the verbal problems. These problem types were prepared for addition, subtraction, multiplication and division separately as each problem type would be on different papers.

The same questions were asked during both individual and group problem solving activities in order to see whether group talks and discussions would affect individual problem solving performance. During the individual work, which lasted for twenty 

classroom. International Journal of Human Sciences, 12(1), 991-1015. doi: 10.14687/ijhs.v12i1.3123

minutes, the teacher did not help to the students about explanation and solution of the problems. However, she evaluated the students' problems solving performances on solely on the work written on their papers.

\section{Findings}

The themes created at the end of the coding process and the findings obtained from the researchers' observations and the teachers' interpretations of observed behaviors are classified. This classification includes observations of how talk occurs during the problem solving process, how talk occurs during the problem solving process as well as the group dynamic created though talk and discussion and its influence on a constructivist learning environment.

\section{What we found about the individual problem solving process}

The individual worksheets were analyzed using three categories: 1) Problems that students could not understand or solve, 2) Problems that students understood but were not solved because of calculation errors, 3) Problems that were solved correctly. The problems consisted of sixteen questions including 4 questions using only words: " $A$ teacher dwelling in the city but works at Sunnyland primary school away from her house. She travels 37 kms to arrive at school every day. How many kilometers in total does this teacher travel in a week except the weekend?";

4 questions with both pictures and words;
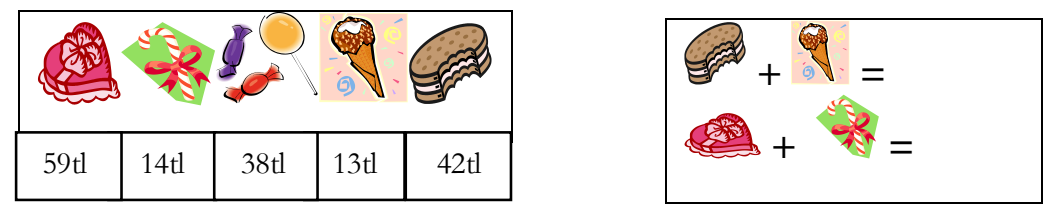

4 questions that provided pictures for students to create their own problems based on the pictures; Create a multiplication problem including the words "green grocer and shopping" by using the picture above and solve it later.

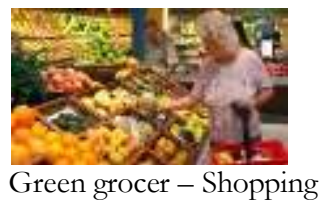

When the students' answers on the individual worksheets were analyzed, it was seen that just seven students solved the first set of problems correctly at the beginning of 
Acar, E., Yllmaz, A. (2015). Building a constructivist social learning environment through talk in the mathematics classroom. International Journal of Human Sciences, 12(1), 991-1015. doi: 10.14687/ijhs.v12i1.3123

the study, while all of the students had correct answers for all of the problems at the conclusion of the study (See Table 1).

Table1.

The answers of the additional problems on individual worksheets

\begin{tabular}{lllllllll}
\hline \multirow{2}{*}{ Student } & \multicolumn{9}{c}{ ADDITION PROBLEMS } \\
& \multicolumn{7}{c}{ First Practice } & \multicolumn{5}{c}{ Second Practice } \\
\cline { 2 - 9 } & 1.st & 2nd. & 3rd. & 4th. & 1.st & 2nd. & 3rd. & 4th. \\
& quest. & quest. & quest. & quest. & quest. & quest. & quest & quest. \\
\hline Yaren & A & B & B & B & C & B & C & C \\
Omay & B & C & B & B & C & B & B & C \\
Murat & A & C & B & B & C & B & B & C \\
Orman & B & C & B & B & C & B & B & C \\
Cansu & C & A & B & B & C & A & B & C \\
Fadik & C & C & A & B & C & C & A & C \\
Meli & C & A & B & B & C & B & B & C \\
Gamze & C & C & B & C & C & A & C & C \\
Ay & B & A & A & C & C & A & B & C \\
Banu & A & A & A & C & C & A & A & C \\
Enis & B & C & A & C & C & A & B & C \\
Asen & C & C & C & B & C & C & C & C \\
Mutlu & C & C & C & B & C & C & C & C \\
Ilke & C & B & C & C & C & C & B & C \\
Isma & A & A & A & B & - & - & - & - \\
\hline
\end{tabular}

A: For the students, who cannot understand the problem; B:For the students, who can understand but cannot reach the correct answer due to the calculation error; $C$; For the students, who can solve the problem.

This result allows us to see how the students' problem solving and sociability have changed during the study and what led to the increase in the students' right answers. But when we analyzed the answers and compared them to the answers of other types of questions, it was seen that there is no such a positive increase. In fact a decrease in the frequency of correct answers occurred. That is, eight students answered the 2nd question correctly on the first individual worksheet while six students answered them correctly on the last one; the number of students answering the problems correctly did not change for the first and the last worksheets.

Another remarkable finding is that while just five students were successful on the problems, which they need to create and solve individually, at the first worksheets, all students created and solved the problems correctly on the worksheets handed out at the end of study. 

classroom. International Journal of Human Sciences, 12(1), 991-1015. doi: 10.14687/ijhs.v12i1.3123

By considering subtraction problems, it can be asserted that the students' success on correct solutions increased and decreased in parallel with the solutions of additive problems.

All the additive problems, which are expected from the students to create and solve, created and solved correctly on the worksheets handed out at the end of study for all students except one (see Table2). Therefore, it can be claimed that the students' problem solving performances increased.

\section{Table2.}

The answers of the subtraction problems on individual worksheets

\begin{tabular}{lllllllll}
\hline \multirow{2}{*}{ Student } & \multicolumn{7}{c}{ SUBSTRACTION PROBLEMS } \\
& \multicolumn{7}{c}{ First Practice } & \multicolumn{4}{c}{ Second Practice } \\
\cline { 2 - 8 } & 1.st & 2nd. & 3rd. & 4th. & 1.st & 2nd. & 3rd. & 4th. \\
& quest. & quest. & quest. & quest. & quest. & quest. & quest. & quest. \\
\hline Yaren & B & B & C & C & B & B & C & C \\
Omay & A & C & B & B & B & B & C & C \\
Murat & C & B & B & C & C & B & C & C \\
Orman & B & C & B & C & B & C & C & C \\
Cansu & A & B & B & C & B & B & B & B \\
Fadik & B & B & C & C & C & B & C & C \\
Meli & A & C & B & C & A & C & B & C \\
Gamze & A & B & C & C & B & B & C & C \\
Ay & A & A & A & B & A & B & B & C \\
Banu & A & A & B & B & A & C & C & C \\
Enis & C & A & B & B & B & A & B & B \\
Asen & C & B & C & C & B & C & C & C \\
Mutlu & C & B & B & C & C & B & C & C \\
\hline
\end{tabular}

A: For the students, who cannot understand the problem; B:For the students, who can understand but cannot reach the correct answer due to the calculation error; $C$; For the students, who can solve the problem.

When we analyzed the amount of correct answers for multiplication problems, we saw that the rate of correct solutions is higher for the first and second problems than the first and second problems in additive and subtractive group comparatively. Also, the rate of increase on the solutions correctly for third and fourth problems is significant. Especially, almost all of students' (13 students) correct answers for fourth problem on the worksheet at the end of study are an expected result if we compare it to the solutions of other types of problems (see Table3). 

classroom. International Journal of Human Sciences, 12(1), 991-1015. doi: 10.14687/ijhs.v12i1.3123

\section{Table3.}

The answers of the multiplication problems on individual worksheets

\begin{tabular}{|c|c|c|c|c|c|c|c|c|}
\hline \multirow{3}{*}{ Student } & \multicolumn{8}{|c|}{ MULTIPLICATION PROBLEMS } \\
\hline & \multicolumn{4}{|c|}{ First Practice } & \multicolumn{4}{|c|}{ Second Practice } \\
\hline & $\begin{array}{l}\text { 1.st } \\
\text { quest. }\end{array}$ & $\begin{array}{l}\text { 2nd. } \\
\text { quest. }\end{array}$ & $\begin{array}{l}\text { 3rd. } \\
\text { quest. }\end{array}$ & $\begin{array}{l}\text { 4th. } \\
\text { quest. }\end{array}$ & $\begin{array}{l}\text { 1.st } \\
\text { quest. }\end{array}$ & $\begin{array}{l}\text { 2nd. } \\
\text { quest. }\end{array}$ & $\begin{array}{l}\text { 3rd. } \\
\text { quest. }\end{array}$ & $\begin{array}{l}\text { 4th. } \\
\text { quest. }\end{array}$ \\
\hline Yaren & $\mathrm{C}$ & $\mathrm{B}$ & $\mathrm{B}$ & A & $\mathrm{C}$ & $\mathrm{C}$ & $\mathrm{C}$ & $\mathrm{C}$ \\
\hline Omay & $\mathrm{C}$ & $\mathrm{C}$ & $\mathrm{C}$ & B & $\mathrm{C}$ & $\mathrm{C}$ & B & $\mathrm{C}$ \\
\hline Murat & $\mathrm{C}$ & $\mathrm{C}$ & A & A & $\mathrm{C}$ & $\mathrm{C}$ & B & $\mathrm{C}$ \\
\hline Orman & $\mathrm{C}$ & $\mathrm{C}$ & A & $\mathrm{C}$ & $\mathrm{C}$ & $\mathrm{C}$ & A & $\mathrm{C}$ \\
\hline Cansu & $\mathrm{C}$ & $\mathrm{C}$ & $\mathrm{C}$ & $\mathrm{C}$ & $\mathrm{C}$ & $\mathrm{C}$ & B & $\mathrm{C}$ \\
\hline Fadik & $\mathrm{C}$ & $\mathrm{C}$ & $\mathrm{C}$ & $\mathrm{C}$ & $\mathrm{C}$ & $\mathrm{C}$ & $\mathrm{C}$ & $\mathrm{C}$ \\
\hline Meli & $\mathrm{C}$ & $\mathrm{C}$ & $\mathrm{C}$ & B & $\mathrm{C}$ & $\mathrm{C}$ & $\mathrm{C}$ & $\mathrm{C}$ \\
\hline Gamze & $\mathrm{C}$ & $\mathrm{C}$ & B & $\mathrm{C}$ & $\mathrm{C}$ & $\mathrm{C}$ & $\mathrm{C}$ & $\mathrm{C}$ \\
\hline Ay & $\mathrm{C}$ & $\mathrm{C}$ & A & A & $\mathrm{C}$ & $\mathrm{C}$ & $\mathrm{C}$ & $\mathrm{C}$ \\
\hline Banu & $\mathrm{C}$ & $\mathrm{C}$ & B & A & $\mathrm{C}$ & $\mathrm{C}$ & $\mathrm{C}$ & B \\
\hline Enis & A & $\mathrm{C}$ & B & $\mathrm{C}$ & B & $\mathrm{C}$ & A & B \\
\hline Asen & $\mathrm{C}$ & $\mathrm{C}$ & $\mathrm{C}$ & $\mathrm{C}$ & $\mathrm{C}$ & $\mathrm{C}$ & $\mathrm{C}$ & $\mathrm{C}$ \\
\hline Mutlu & $\mathrm{C}$ & $\mathrm{C}$ & $\mathrm{C}$ & B & $\mathrm{C}$ & $\mathrm{C}$ & C & C \\
\hline Ilke & C & C & B & C & C & C & C & C \\
\hline Isma & A & C & A & A & A & C & B & C \\
\hline
\end{tabular}

A: For the students, who cannot understand the problem; B:For the students, who can understand but cannot reach the correct answer due to the calculation error; $C$; For the students, who can solve the problem.

In division questions, slight increases and decreases are seen for the first, second and third questions if we compare the beginning worksheets with the end ones. For the first question, just Orman couldn't solve the problem because of the calculation error. The second question couldn't be solved by five students due to the calculation errors in the second practice when it is compared to the first one. And the difference between the first and second practices for the third question was three unsolved problems, which couldn't be solved because of the lack of understanding and the calculation errors.

Although only eight students created problems by using the pictures and solved them correctly at the beginning of the study, all students except two could create and solve the expected problems at the end (see Table4). 

classroom. International Journal of Human Sciences, 12(1), 991-1015. doi: 10.14687/ijhs.v12i1.3123

\section{Table4.}

The answers of the additional problems on individual worksheets

\begin{tabular}{lllllllll}
\hline \multirow{2}{*}{ Student } & \multicolumn{8}{c}{ DIVISION PROBLEMS } \\
& \multicolumn{7}{c}{ First Practice } & \multicolumn{5}{c}{ Second Practice } \\
\cline { 2 - 9 } Yaren & C & C & C & C & C & C & A & C \\
Omay & C & C & C & C & C & C & C & C \\
Murat & C & C & B & A & C & B & B & A \\
Orman & C & C & C & C & B & C & C & C \\
Cansu & - & - & - & - & C & C & A & C \\
Fadik & C & C & C & C & C & C & C & B \\
Meli & C & C & C & B & C & B & B & A \\
Gamze & C & C & C & C & C & C & C & C \\
Ay & C & C & A & B & C & B & A & C \\
Banu & C & C & B & C & C & C & A & C \\
Enis & A & C & A & A & A & B & B & A \\
Asen & C & C & C & C & C & C & C & C \\
Mutlu & C & C & C & C & C & B & B & C \\
Ilke & - & - & - & - & $C$ & $C$ & C & C \\
Isma & C & C & A & A & C & C & B & C
\end{tabular}

A: For the students, who cannot understand the problem; B:For the students, who can understand but cannot reach the correct answer due to the calculation error; $C$; For the students, who can solve the problem.

In the analysis of the students' words in unstructured interviews, it appeared that the students perceived the content of some questions to be incomprehensible, causing difficulty solving particular questions. Moreover, it was emphasized that the questions that contained only verbal explanations (without descriptive pictures or visual elements) were difficult to understand. At the end of the study, the students' correct solutions on the assigned worksheets decreased. Therefore, we hypothesize that because the end of the study coincided with the end of the term, the correct solutions decreased. We assume that this decrease in correct solutions results from the students' low concentration at the end of term. In the study most of the students identified the word only problems difficult where the other types of problems were not seemed difficult (see Table 5). 
Acar, E., Yilmaz, A. (2015). Building a constructivist social learning environment through talk in the mathematics classroom. International Journal of Human Sciences, 12(1), 991-1015. doi: 10.14687/ijhs.v12i1.3123

Table5.

The number of students, who cannot solve the problems due to their difficulties

Prob. No Addition Subtraction Multiplication Division

\begin{tabular}{ccccc}
\hline 1 & 1 & 2 & 2 & 1 \\
2 & 4 & 4 & - & - \\
3 & 4 & - & 3 & 4 \\
4 & - & 2 & 1 & - \\
None & 6 & 7 & 9 & 8 \\
\hline
\end{tabular}

\section{Problem Solving Practices situated as in-group talk}

\section{What kind of learning environment was constructed in the groups during}

\section{problem solving?}

In the study, the teacher created a conducive environment by encouraging students to talk during the videotaping of their group. While the teacher was working with the group being videotaped the other students were occupied with the regular classroom tasks. The teacher also intervened and explained the problems when required, but generally gave students independence while working in their groups in order to make students feel comfortable with their abilities to concentrate to solve the problems.

\section{Problem solving practices carried out in the form of in-group speech}

What was observed in the problem solving processes and how did talk occur?

When we examined the groups' behaviors in the problem solving process, we saw that group leaders emerged naturally in three groups, while there was no group leader in one group. In the groups with a group leader, students did not participate to the problem solving task equally, instead, the students playing the leadership roles led the tasks of the other group members and acted individually in problem solving. Yet, it was also group leaders who expressed opinions and manipulated the solutions of the problems, which were difficult to solve.

In two of the groups wherein a student took a leadership role, the students playing the leadership role manipulated the problem solving process through talking with the other group members shortly while in the groups that had two students vying for the leadership role, the problems were solved through talk among these two students. In the fourth group, which had no an explicit leader, almost all of the group members expressed their ideas for solving the problems and contributed to the solution process. The talk occurred through each group member expressing his/her ideas about the problems or 
Acar, E., Yllmaz, A. (2015). Building a constructivist social learning environment through talk in the mathematics classroom. International Journal of Human Sciences, 12(1), 991-1015. doi: 10.14687/ijhs.v12i1.3123

their solutions, specifically they discussed if the given elements in the problems are true, solvable and understandable.

\section{Discussions Initiated by a group leader}

The ways in which talk was initiated and manipulated by group members were constructed in two ways. First, group leaders talked about the problems, and second, one of the group members responded to the leader student's ideas. In the groups, talk occurred when some students disagreed with the leader's ideas, but when group members approved of the leader's ideas, the problems were solved through a process that included little talking. This occurred because the group leader often solved the problem individually and the other students passively agreed.

In the group, which had at least two dominant students, even in instances where dominant students agreed on how to find a solution to a problem, the students vying for the leadership roles still struggled to accept one another' ideas. It was seen that this situation was the result of students' perceptions of each other as an opponent. Thus, they expressed more ideas in order to establish superiority over another student's solutions. The talking ratio of the group having two dominant students was higher than the ratio of the groups having only one leader student. Therefore, it can be asserted that two dominant characters are more effective in order to create talk and discussion in a small group than a single dominant character. However, in the group having two leader students, the other group members' participations were limited. According to the interviews, this limited participation was occurred because the non-dominant students were concerned that their ideas were not academically inadequate, they were afraid of making mistakes, and they thought that their ideas would be neglected by the group leader(s).

\section{Group work having one dominant student as a leader}

In the study, it was seen that the students who played a leadership role took charge of problem solving and their solutions were accepted without much questioning by the other students in groups. This acceptance also prevented the realization of the leader students' mistakes. This might provide evidence that the other students in the groups (aside from the group leader) trust the leader's thinking and solutions. Therefore, the non-leader students do not make an effort to think about or solve the problem. Moreover, the high academic success of the dominant students in general might also be a significant factor explaining the other students' confidence in the group leader. Some example dialogues below provide support for these findings. 
Acar, E., Yilmaz, A. (2015). Building a constructivist social learning environment through talk in the mathematics classroom. International Journal of Human Sciences, 12(1), 991-1015. doi: 10.14687/ijhs.v12i1.3123

\section{Group 2 - Addition- Questions 2}

Problem: A teacher travels 37 kems to arrive at school every day. How many kilometers in total does this teacher travel in a week except the weekend?

Ísma: ... $34 \mathrm{kms}$

Enis: ... 34 kms for going and 34 kms for returning.

Gamze: ...74 kms in a day in total. Therefore we will multiply 74 by 7. (She is playing a group leader role. Because she ignored that the teacher worked just in weekdays not in weekend, she multiplied 74 by 7 . But, the other group members did not recognize this mistake).

\section{Group 1 - Multiplication - Question 4}

... (The group's leader student, Asen, seems to have his friend Orman's trust with his high success in the class and the leadership position in the group.)

Orman: ... should write Asen's problem sentence.

Banu: Why...?

Orman: I am sure that his sentence is truer.

Aside from the adoption of the group leader's ideas unquestioningly, it is observed that the other students expect the leader's approval of their ideas of problem solving as well. This situation led to the tendency for the group leader to make the final decision.

The students, did not have ideas related to the solution of the problem or those who did not engage with the problem or just listened to the discussions of other group members in solving the problems, repeated the ideas put forward by the leader in exactly the same manner as the leader in the solution process. We can see the repetition of the opinions in the dialogues between two students in Group 3 about the same question asked in Group 2.

\section{Group 3 - Division - Question 3}

$\cdots$

Yaren: Because we need to prepare 2 kilogram-packets ... should divide 168 by 2.

Meli: We should divide 168 by 2.

While the group was solving the problem, it was seen that the student undertaking the leadership role led the entire problem solving process in the group. In such cases, the other group members were passive and they abided by the decision of the leader. They generally repeated the leader's ideas and words. When the leader explained the way to find the solution or simply provided the solution, no talk was observed except a few simple sentences. Because all of the group members were not active and did not share their ideas 
Acar, E., Yllmaz, A. (2015). Building a constructivist social learning environment through talk in the mathematics classroom. International Journal of Human Sciences, 12(1), 991-1015. doi: 10.14687/ijhs.v12i1.3123

and solutions in the groups, it is not possible to conclude that learning was constructed for each group member.

The group leaders attempted to control the first efforts to solve the problems or they attempted to solve the problems on their own as they did not want to allow the other students to speak. However, the leaders took account of other students' opinions and acted in a more facilitory way about finding a solution together with other students if the problem could not be solved easily on their own or when they began to solve a new question.

The students undertaking leadership roles determined the roles of other students in the group as well; this was probably because of their conceptions of the responsibility of leadership. In the groups that the leader student was dominant, the leader still shared some tasks with the other group members. Additionally, some group leaders cared about the equal task sharing in the group.

\section{Group 4- Addition - Question 1}

IIlke: There are 4 questions in this activity. We are three people, so everyone reads one question, which are different from each other. We analyze the last question together and write the solutions in order.

Cansu: Illke "You read the first question," please!

\section{The group work having at least two leader students.}

In the groups having at least two dominant characters, these two students exchanged their opinions with one another while they were reading and solving the assigned problem for the group. Therefore, these students were naturally active in talking to each other and solving the problems.

\section{Group I- Addition- Question 3}

...What is the total population of this village?

(Asen and Mutlu were the dominant characters in the group)

Mutlu: What are you doing? (He warned him)

Asen: We can find the population of village by adding all the given numbers.

Mutlu: The numbers of men and children are not clear in the problem. So, we have to calculate them first.

Asen: No!! We must add all the given numbers.

... While two dominant characters in the group were discussing about the solution, the others were just watching. The other group members did not make any suggestion or correction for the solution.) 

classroom. International Journal of Human Sciences, 12(1), 991-1015. doi: 10.14687/ijhs.v12i1.3123

Even though this example led to the other students remaining silent during the leader students' sharing their ideas about the problems, it was seen that the talk of two leader students to each other was more effective than the talk of just one leader on the rest of the group's learning. What made us realize this was that one or two of the other students' approval of what the leaders said and the expression of their ideas with one of two words at the least.

\section{Group I - Subtraction - Question 3}

... (Asen and Mutlu have the leadership roles in the group)

Mutlu: The long border is $128 \mathrm{~m}$ and there are two long borders.

Asen: There are two $128 \mathrm{~m}$.

Orman: Yes, $128 m$.

Asen: There are two short borders also as 94 metres long. Let's add all of them. (They added all numbers and found 444 metres).

Mutlu: Let's subtract 448 from 548.

Orman: It should be 444, not 448

Asen: Why are we subtracting?

Orman: Shouldn't we add them?(Mutlu is reading the problem again)

Mutlu: ... fencing it with double fence wire. So, we must multiply the perimeter by two.

Orman: Let's multiply 444 by 2 ...

In the groups having two student-leaders, it was recognized that the leaders had some trouble ideas accepting the solutions offered by one another's' ideas. This disclamation can be clearly seen in the example below.

\section{Group I- Subtraction- Question 2}

$\cdots$

Mutlu: ... for making "3 cakes" to the question, we should multiply 2,5 kg by 3 .

Asen: No, first we must convert kilogram into gram. Then,... multiply the result by 3.

Mutlu: We must multiply 2,5 $\mathrm{kg}$ by 3 and subtract 6800 from the result.

Asen: We must convert kilogram into gram...

\section{The talk developing naturally in a group}

Although at least one or two leader students appeared in three of four participant groups and they led the problem solving process, a natural discussion platform including all group members' talk occurred in only one group. 

classroom. International Journal of Human Sciences, 12(1), 991-1015. doi: 10.14687/ijhs.v12i1.3123

The students' sociable and participative personalities may be effective for developing a discussion in a group where all students contribute and talk without a group leader. According to the observations of the classroom teacher, the students in the group without a leader were willing to help not only their group, but in some cases they also helped the students in the other groups. Their assistances mostly focused on explaining incomprehensible subject matter to their friends.

\section{Group I- Addition- Question 3}

\begin{tabular}{|l|l|}
\hline Types of shirt & Number of order \\
\hline Kids & 6 dozens \\
\hline Women & 9 dozens \\
\hline Men & 7 decks \\
\hline
\end{tabular}

The owner of a shirt shop realized that the shirt types got less...how many shirts did she order in total? (All group members are analyzing the given knowledge in the question and are expressing their opinions solution together.)

Asen: 6 dozens

Orman: It should be 6 times 12. There are 12 in a dozen.

Orman: Let's calculate it. But, no mistake please!

Asen: Let's do mental calculus (they are calculating it together).

Murat: There are 10 in a deck

Banu: 7 times 10.

Orman: Because the problem asks "bow many shirts in total" we must add all the multiplication results.

Murat: Yes we must.

As seen in the example above, in the groups without a group leader talk occurred through students completing another student's ideas or solution steps; students were building on one another's ideas. While each person's contribution in the group was sometimes taking place as correcting the mistake, it sometimes occurred as giving new ideas to another student or explaining another student's ideas. This situation may be a result of the students' lack of full content and strategy knowledge about problem solving. Also, in groups that did not have a student with good leadership skills or sufficient subject matter knowledge, the problems could not be understood clearly and thus the problems were not solved.

It was conspicuous that not all problems could be solved even when the students could talk about a problem comfortably in the groups without a group leader. This situation can be seen in the dialogue below. 
Acar, E., Yilmaz, A. (2015). Building a constructivist social learning environment through talk in the mathematics classroom. International Journal of Human Sciences, 12(1), 991-1015. doi: 10.14687/ijhs.v12i1.3123

\section{Group 3 - Addition - Question 2}

... 37 kilometers for coming to school during the week days except weekend. How many kilometers does she travel in a week in total (think round trip)?

Murat: ...must add 37 with 37.

Yaren: ... must multiply them.

Murat: ... need to add them.

Yaren: ... must multiply them.

Murat: There is no other 37 to multiply.

Yaren: ... must multiply them as it says round trip. The result is 74 .

Meli: Then we must do $74-7 .$. (No solution)

Talk occurred naturally in the leaderless group discussions, in these discussions problems were explained, solutions were discussed and opposite ideas were shared. However, in the groups with leaders talk did not occur as naturally but despite the leadership role in groups, many students noted that they were able to recognize and correct mistakes on their individual worksheets. This situation was mentioned by Murat, Cansu and Omay during an unstructured interview of the teacher with her students.

\section{Teacher's unconstructed interview with the group after the problem solving activity}

According to the unstructured interviews with the participant students, it was noticed that the dialogues developed in the groups during the problem solving process affected some students socially. Some students' expressions showed that group members knew each other better and they cared about each other's ideas more after spending some time together in the problem solving activities.

\section{Group 4 - Subtraction - Question 1}

Cookies

\begin{tabular}{|l|l|l|l|}
\hline $1 \mathrm{~kg}$ & $1 \mathrm{~kg}$ & $1 \mathrm{~kg}$ & $1 \mathrm{~kg}$ \\
\hline $19 \mathrm{tl}$ & $14 \mathrm{tl}$ & $18 \mathrm{tl}$ & $24 \mathrm{tl}$ \\
\hline
\end{tabular}

Cansu: We must subtract $7 \mathrm{~kg}$ from $12 \mathrm{~kg}$.

Ilke: ... must multiply 19 by 12 .

Cansu: You are right. Then, ... must subtract all the results, which we got.(Her group friends told their ideas about the problem solution and solved it. Omay just watched this process instead of participating the problem solving activity).

(The teacher's unconstructed interview) 
Acar, E., Yilmaz, A. (2015). Building a constructivist social learning environment through talk in the mathematics classroom. International Journal of Human Sciences, 12(1), 991-1015. doi: 10.14687/ijhs.v12i1.3123

Teacher: Did you able to solve this question on the individual worksheets? Now? (in the group work) Why?

Omay: I couldn't make sense the first question in the individual practice. So, I couldn't solve it. But, I understood its' solution after Illke's explanations and later helped my other group friends for solving it.

As seen in the dialogue above, all students pointed out that they could not solve the question when they did not understand it on individual worksheets. However, they asserted that they could ask their group member's questions about areas they did not understand during the group study, and therefore they could make some contributions to the problem solving process. Furthermore, the group leader encouraged or discouraged other students' participation by pointing out specific ways of solving the problem.

\section{Conclusion}

The aim of this study was to provide empirically grounded conceptualization of creating a constructive classroom environment via talk and discussion groups. We intended to see if the students could show different performances on problem solving in this kind of constructive classroom environment. Therefore, we focused on the group talk and discussions to understand the students' actions and interactions during the process of problem solving. In this respect, we determined three different group categories, taking into account the leadership roles seen in the small groups such as a single leader in a group, shared leadership roles with two people in a group and groups having no leader. Our data showed us that group talk and discussions in the problem solving process were not lively and productive most of the time if there was not a leader in the group. Not all cooperative learning strategies increase student achievement (Slavin, 1987b). Additionally, if there was no leader the group remained incapable of producing an idea for the solutions of problems. As well as the group members' lack of contribution to the solutions, the proposed ideas did not be accepted by other group members. Hence, the problems couldn't be solved in the group work including the addition and subtraction problems.

During the problem solving processes in the groups it was seen that the students showing dominant personality traits claimed responsibility for the leadership role in the groups. The leader students especially preferred to read the questions to the group members. Only the student undertaking the leadership role in the fourth group told to others that each one needs to read one question as a part of his or her distribution of the tasks. However, even this situation shows that one student has taken on a leadership role. 
Acar, E., Yilmaz, A. (2015). Building a constructivist social learning environment through talk in the mathematics classroom. International Journal of Human Sciences, 12(1), 991-1015. doi: 10.14687/ijhs.v12i1.3123

Another conspicuous point about group leaders is that the students undertaking the leadership roles were also academically successful students. We surmise that it was easier for group members to accept the leadership roles of students who are academically successful in their classrooms.

In the groups with two leaders it was observed that the leaders had trouble agreeing and accepting each other's' ideas about problem solving. In relation to the leadership role, the students undertaking the leadership role always wanted to lead the group themselves. But, even if a group's leader made other students passive, it was seen that the students in small groups needed to be led by a leader. Some group leaders tried to help their group by explaining the given values and non-understandable parts in problems repeatedly and to incorporate the group in the problem solving process. The group leaders' preferences of individual problem solving, their unwillingness towards other group members' interventions, their tendency not to listen to the other members' ideas or include others in the problem solving process showed how the social structure is formed and maintained in the groups. According to this social structure, it became necessary for the leader to be more facilitator to other group members in order to ensure other students are willing to share their ideas without discouraging responses from the leader.

Also, determination of the tasks in a small group by the group leader and some group leaders' attempts to share the tasks equally points out the group leaders' tendency to take responsibility of group organization. Another interesting point was the nonleadership students' unquestioned acceptance of the solution methods proposed by the students undertaking leadership role in some groups. In this situation, it would be asserted that expected and desired knowledge structuring did not occur or this structure was not reflected in groups with a dominant group leader. Nevertheless, interestingly, the students in groups expected approval for their ideas from the students who adopted the leadership role. The group leader's approval and the last decision about the solutions show a created passive social structure in the groups. As a requirement of this passive structure, the students' ideas about the solutions of problems repeated the other students' thoughts and words. Even if the passive students in the groups projected an image of not benefitting from the creation of a constructive classroom atmosphere which allowed for talking and discussion, it was observed that group members got to know each other better and valued each other's' ideas more so all students benefitted in this environment.

When the academically unsuccessful students were asked about the reasons for their non-participation or troubles during the problem solving, they expressed that they 
Acar, E., Yllmaz, A. (2015). Building a constructivist social learning environment through talk in the mathematics classroom. International Journal of Human Sciences, 12(1), 991-1015. doi: 10.14687/ijhs.v12i1.3123

had made many mistakes during the individual problem solving process and therefore had been shy of sharing their ideas during the group discussions. These findings support the Berliner and Calfee's (1996) emphasis about some theorists' ideas of that cooperative group may not lead to enhanced participation for low-status students.

In general, the dominant leadership behavior was observed in the first, second and third groups during the study. Group leaders preferred to solve the problems individually without getting the others' opinion instead of act together with others in the group. Also, it is seen that the group leaders did not trust the other group members' opinions and therefore did not take into consideration their suggestions and contributions towards the solution of problems. But, in the fourth group, the group leader organized the problem solving process by sharing out the tasks to all group members equally. Besides this, the group leader got other group members' opinions about problem solving, and then he explained the problems when he recognized that was a problem among group members with understanding the question. He tried to get other group members' approvals about the way of solving the problems. Also, the classroom teacher observed the groups and noted that there was nobody undertaking leadership role in third group. Without any leader other group members couldn't solve the problems because of disorientation. For this reason, it is observed that the group members' interplays are very limited. All these findings may be explained by Cohen's (1986) theoretical framework ground on Berger, Cohen, and Zelditch's (1972) expectation states theory, that states that cooperative small-group structures make status differences among students remarkably. According to the theory, achievement differences are likely to become more evident, especially on certain types of tasks) and status differences may increase. These status differences cause to high achievers' domination and low-status differences, so high achievers would dominate, and low-status students would remain relatively passive (cited in Berliner and Calfee, 1996).

Also, in the first group it was seen that there was a competition among two group leaders and they prohibited (did not let) other group members from sharing their opinions. Therefore, from the second week of the study the seating of Mutlu in first group was switched with Murat's joining the third group. Murat preferred to be passive because of the group leader's dominant behaviors after changing his seating from the first group, while he could solve the problems without the group leader's guidance and support and could contribute to the problem solving in the third group. Mutlu undertook the third group's leadership after he switched his seating and managed the problem 
Acar, E., Yilmaz, A. (2015). Building a constructivist social learning environment through talk in the mathematics classroom. International Journal of Human Sciences, 12(1), 991-1015. doi: 10.14687/ijhs.v12i1.3123

solving process and solved the problems individually in the group by acting as a dominant leader.

There was a spontaneous group leader in each group. Although three group leaders tried to solve the problems individually, the leader of fourth group paid special attention to other group members for understanding the problems and their supports about solving them.

In this study, it is examined that how discussion and talk environment occur in groups wherein three different types of leadership roles were observed. The type of leadership role either created a constructivist learning environment or constrained a constructivist learning environment, and affected the discussion and learning of students in different groups. Constructivist learning environments should provide access to shared information and shared knowledge-building tools to help learners to collaboratively construct socially shared knowledge (Jonassen, 1999, p.228).

We observed that group talk and discussions have positive effects on constructing learning of how to solve math problems. Specifically we say that group members were motivated through contributing correct answers to the problem solving process, which increased his/ her motivation to contribute more to the group and enhanced eagerness to learn. All these observations support that learning most naturally occurs by teams of people working together instead of isolation (Jonassen, 1999).

In accordance with the results it can be claimed that the students' talk and discussions in some problem solving activities may affect the average or under average students' awareness of effective problem solving and their ability to devise solutions positively.

\section{References:}

Adams, D.M. \& Hamm, M.E. (1990). Cooperative Learning Critical Thinking and Collaboration Across the Curriculum. Charles C Thomas Publisher, Springfield, IL, USA.

Adams, D.M. \& Hamm, M.E. with the collaboration of Drobnak, M \& Lazar A (1996). Cooperative Learning-Critical Thinking and Collaboration Across the CurriculumSecond Edition, Charles C Thomas. Publisher, Springfield, IL, USA. P.119.

Berliner, D. C. \& Calfee, R. C. (1996). The informal curriculum. Handbook of Educational Psychology, pp. 622-673. Routledge, Taylor \& Francis Group. 
Acar, E., Yllmaz, A. (2015). Building a constructivist social learning environment through talk in the mathematics classroom. International Journal of Human Sciences, 12(1), 991-1015. doi: 10.14687/ijhs.v12i1.3123

Bligh, D. A. (1986). Developing Skills for Small Group Work. Chapter 6. In (Ed.) Donald Bligh, Teach Thinking by Discussion. Published by SRHE \& NFER-NELSON At the University, Guildford, Surrey GU2 5XH. pp.19-25.

Blumenfeld, P. C., Marx, R. W., Soloway, E. \& Krajcik, J. ( 1996). Learning with peers: From small group cooperation to collaborative communities, Educational Researcher, 25, 8, $37-40$.

Cohen, E.G. (1994). Restructuring the classroom: Conditions for productive small groups. Review of Research, 64, 1, 1-35. Doi: 10.3102/00346543064001001

Cunningham, D. (2011) Improving Teaching with Collaborative Action Research. ASCD., Alexandra, VA, USA. pp. ix-195. (used p.3).

Emmer, E.T. \& Gerwels, M.C. (2002). Cooperative learning in elementary classrooms: Teaching Practices and Lesson Characteristics. The Elementary School Journal, 103, 1, 75-91.

Fisher, D., Frey, N. \& Rothenberg, C. (2008). Content-area conversations. How to plan discussion-based lessons for diverse language learners. Association for supervision and Curriculum Development (ASCD). Alexandria, VA, USA. pp. ix-174.

http://www.ascd.org/publications/books/108035/chapters/Why-Talk-Is-Important-inClassrooms.aspx

Henning, J. E., Stone, J.M. \& Kelly, J.L. (2009). Using Action Research to Improve Instruction: An Intearactive Guide for Teachers. New York: Routledge-Madison Ave, Taylor \& Francis, pp. ix-203.

Jane, B. (2000). Let's go tinkering. In Classroom Connections practical activities for the primary classroom, Vermont, Victoria: Research Publications, April-June, pp. 140-16.

Jonassen, D. H. \& Rohrer-Murphy, L. (1999). Activity theory as framework for designing constructivist learning environments. Educational Technology Research and Development, 47, I, pp. 61-79, ISSN 1042-1629.

Jonassen, D. H. (1999). Designing constructivist learning environments. In C.M. Reigeluth (Ed.), Instructional design theories and models: A new paradigm of instructional theory, II, pp. 215-239.

NJ: Lawrence Erlbaum Associates, Inc.

Kim, B. (2001). Social constructivism. In M. Orey (Ed.), Emerging perspectives on learning, teaching, and technology. Retrieved electronically from:

http://www.coe.uga.edu/epltt/SocialConstructivism.htm

Martin, L., Towers, J. \& Pirie, S. (2006). Collective mathematical understanding as improvision, Mathematical Thinking and Learning, 8, 2, 149-183.

McRobbie, C. \& Tobin, K. (1997). A social constructivist perspective on learning environments. International Journal of Science Education, 19, 2, 193-208.

Nelson, L. M. (1999). Collaborative problem solving. In C.M. Reigeluth (Ed.), Instructional design theories and models: A new paradigm of instructional theory, II, pp. 241-269. NJ: Lawrence Erlbaum Associates, Inc. 

classroom. International Journal of Human Sciences, 12(1), 991-1015. doi: 10.14687/ijhs.v12i1.3123

Piggott, J. (1997). Developing good team-working skills. Available electronically at http://nrich.maths.org/6933

Rogoff, B. (1998). Cognition as a collaborative process. In W. Damon (Series Ed.), D.

Kuhn and R. S. Siegler (Ed.), Cognition, perception and language. Handbook of Child Psychology, Vol.2, (5th ed.), pp.679-744. New York: John Wiley.

Rubin, K. H., Bukowski, W. M. \& Parker, J.G. (1998). Peer interactions, relationships, and groups. In Damon W. \& Eisenberg N. (Ed.), Social emotional and personality development. Handbook of Child Pyschology: Vol. 3. (5th ed.), pp.619-700. New York: Wiley.

Schoenfeld, A. H. (1992). Learning to think mathematically: Problem solving, metacognition, and sense-making in mathematics. In D. Grouws (Ed.), Handbook for Research on Mathematics Teaching and Learning, pp. 334-370. New York: MacMillan.

Slavin, R. E. (1987a). Cooperative learning: Where behavioral and humanistic approaches to classroom motivation meet. The Elementary School Journal, 88, 1, 29-37.

Slavin, R. E. (1987b). Developmental and motivational perspectives on cooperative learning: A reconciliation. Child Development, 58, 5, 1161-1167.

Wagner, R.H. \& Arnold, C.C. (1965). The process. Chapter 5. (pp.68-89). Handbook of group discussion. Pp. 1-285.(2nd ed.) Boston, USA: Houghton Mifflin Company.

Weber, K., Maher, C., Powell, A. \& Lee, H. S. (2008). Learning opportunities from group discussions: Warrants become the objects of debate. Educational Studies in Mathematics, 68, 3, 247-261. 